\title{
Percepções de Incerteza em um Sistema de Planejamento e Controle: um Estudo Comparativo Brasil - Inglaterra
}

\author{
Ana Carolina Pimentel Duarte da Fonseca
}

\section{RESUMO}

Este estudo teve por objetivo detectar o impacto de diferenças culturais em um sistema de planejamento e controle. Para atender a este propósito, foi realizada uma pesquisa qualitativa na subsidiária brasileira de uma empresa multinacional britânica. Visando a compreender mais profundamente a maneira como ocorria a interação da cultura nacional com práticas de controle gerencial, selecionou-se uma dimensão cultural identificada por Hofstede (1980) em seu estudo a respeito de valores em mais de 50 países. A dimensão escolhida foi fuga à incerteza, a qual é definida como a extensão em que os membros de uma cultura se sentem confortáveis com a incerteza e com a ambigüidade, aspectos estreitamente relacionados com o sistema de planejamento e controle. A pesquisa realizada baseou-se em entrevistas que visavam a investigar de que modo os informantes lidavam com a incerteza em seu sistema de planejamento e controle. Onde a teoria sugeria mais de um comportamento provável, foi possível selecionar uma alternativa. Finalmente, enquanto alguns pontos previstos na literatura puderam ser confirmados, outros mostraram-se opostos ao que seria esperado, sugerindo a influência de outros fatores.

Palavras-chaves: cultura organizacional; cultura do Brasil; cultura da Inglaterra; controle gerencial.

\begin{abstract}
This study aimed to detect the impact of cultural differences in a planning and control system. In order to reach this objective, a qualitative research was realized in a Brazilian subsidiary of an British multinational corporation. In order to understand more deeply the way the interaction between the national culture and management control practices occured, it was selected a cultural dimension identified by Hofstede (1980) in his study about values of people in over 50 countries. The dimension chosen was uncertainty avoidance, which is defined as the extent to which the members of a culture feel themselves comfortable with uncertainty and ambiguity, aspects strictly related to the planning and control system. The research was based on interviews which sought to investigate the way the informants dealt with uncertainty in their planning and control system. Where the theory suggested more than one possible behaviour, an alternative could be selected. Finally, the reports were able to confirm some results antecipated in the literature while others seemed to be opposite to what was expected, suggesting the influence of other factors.
\end{abstract}

Key words: organizational culture; culture of Brazil; culture of England; management control. 


\section{INTRODUÇĀO}

O presente estudo foi realizado com o objetivo de detectar o impacto de diferenças culturais no sistema de planejamento e controle. Para atender a este propósito, foi realizada uma pesquisa na subsidiária brasileira de uma empresa multinacional britânica, visando a avaliar a aceitação, por parte da subsidiária, do sistema de planejamento e controle elaborado pela matriz (Fonseca, 1997). A pesquisa de campo no Brasil consistiu em entrevistas em profundidade com quase todos os funcionários da subsidiária, permitindo uma visão muito significativa do grupo brasileiro. Antes, porém, foram efetuadas algumas entrevistas na matriz britânica, as quais não só facilitaram a compreensão do funcionamento do sistema de planejamento e controle dentro do grupo multinacional, como também permitiram captar alguns traços da imagem da subsidiária brasileira perante a matriz.

Para compreender mais especificamente de que forma ocorria a interação da cultura nacional com as práticas de controle gerencial, selecionou-se uma das dimensões culturais identificadas por Hofstede (1980): fuga à incerteza.

Assim, basicamente, o estudo visou a aprofundar o conhecimento a respeito do impacto que os principais aspectos da dimensão fuga à incerteza poderiam produzir no desenho e na aceitação do sistema de planejamento e controle de uma multinacional, sempre com a preocupação de comparar os resultados obtidos com aqueles que haviam sido antecipados na literatura. Enfatizando o aspecto simbólico das culturas organizacionais e do sistema de planejamento e controle, optouse pela aplicação de um método de pesquisa qualitativo, por considerá-lo mais adequado para captar significados e relacioná-los de forma coerente.

\section{Revisão de Literatura}

\section{Os Estudos de Hofstede}

Para Sondergaard (1994) a pesquisa de Hofstede (1980) Culture's Consequences parece ter sido relevante para efetuar mudanças no enfoque dos estudos crosscultural. Segundo Sondergaard (1994) em uma análise do índice de citações de ciências sociais foram encontradas 1.136 citações de Culture's Consequences em jornais, das quais mais de $80 \%$ são posteriores a 1986. Da mesma forma, Adler e Bartholomew (1992) detectaram que, a partir da segunda metade dos anos 80, os 
estudos nas áreas internacionais de comportamento organizacional e gerência de recursos humanos tenderam a reconhecer a importância da cultura e de seu impacto. Em sua opinião, esta tendência pode ter sido ocasionada pela influência da pesquisa de Hofstede (1980) sobre as demais da área, principalmente após 1986.

O estudo de Hofstede (1980) analisou grande quantidade de dados sobre valores de pessoas em mais de 50 países ao redor do mundo, partindo da suposição levantada por vários antropólogos americanos da primeira metade do século 20: todas as sociedades enfrentam os mesmos problemas, só variando as respostas. O projeto foi conduzido entre 1967 e 1973, contando com 116 respondentes, que trabalhavam em subsidiárias de uma corporação multinacional, a IBM. De acordo com Hofstede (1980), as amostras eram semelhantes em todos os aspectos, exceto nacionalidade, o que faria com que o efeito de diferenças nacionais ficasse bem claro.

Hofstede (1994) acrescenta que, além do primeiro projeto, outros dois foram realizados entre estudantes de 10 e 23 países, respectivamente. Hofstede (1991) concluiu que a análise estatística das respostas das questões sobre valores revelou problemas comuns mas soluções peculiares a cada país, em algumas áreas básicas por ele denominadas dimensões. Segundo Hofstede (1991) uma dimensão agruparia um número de fenômenos em uma sociedade que se descobriu, empiricamente, que ocorrem em combinação, mesmo que, à primeira vista, não pareça haver uma necessidade lógica de ficarem juntos. Para cada dimensão separada, os extremos opostos descrevem tipos ideais; entretanto os índices obtidos pelos países nas dimensões mostram que a maior parte dos casos reais se situa entre os extremos.

As quatro primeiras dimensões encontradas foram interpretadas da seguinte forma por Hofstede (1983). Distância do poder trataria da forma como uma sociedade lida com desigualdades entre as pessoas. Individualismo versus coletivismo relacionar-se-ia com o grau de interdependência que uma sociedade mantém entre as pessoas. Fuga à incerteza consistiria no grau em que os membros de uma sociedade se sentem desconfortáveis com a incerteza e a ambigüidade. Masculinidade versus feminilidade abordaria a forma como cada sociedade aloca papéis sociais aos sexos. Finalmente, a última dimensão, orientação de longo prazo versus orientação de curto prazo, encontrada apenas em 1987, utilizando questionário desenhado por pesquisadores chineses, lidaria, segundo Hofstede (1994), com a busca da virtude. Valores associados à orientação de longo prazo seriam frugalidade e perseverança; valores associados à orientação de curto prazo seriam respeito pela tradição, cumprimento de obrigações sociais e proteção da face $^{(1)}$. 


\section{A Dimensão Cultural Fuga à Incerteza}

Hofstede (1991, p. 110) afirma: “como seres humanos, nós todos temos de encarar o fato de que não sabemos o que acontecerá amanhã: o futuro é incerto mas temos que conviver com isto". Assim, como o tempo corre numa única direção, não seria possível desfazer o que já foi feito, nem se poderia prever o que está por vir. Então, a questão fundamental levantada por esta dimensão seria: como a sociedade lida com a incerteza sobre o futuro; se ela tenta controlá-lo ou o deixa acontecer; a extensão em que seus membros seriam capazes de lidar com a incerteza, sem apresentar estresse excessivo. Desta forma, alta fuga à incerteza levaria as pessoas a abraçarem crenças que prometem certezas; a manter instituições que protegem tradições e costumes; a tentar gerenciar situações imprevisíveis adotando um código rígido de comportamento, regras explícitas e regulamentos, rejeitando idéias novas, e aceitando a existência de verdades absolutas. O comportamento inverso indicaria tolerância para circunstâncias novas e ambíguas.

Hofstede (1980) observa ainda que a incerteza é conceito chave nas teorias organizacionais modernas. As sociedades distintas lidariam com incerteza de formas diferentes, afetando a maneira como elas constroem suas organizações. $\mathrm{O}$ conceito de incerteza estaria freqüentemente ligado ao conceito de ambiente, que geralmente inclui tudo o que não está sob controle direto das organizações. Seria uma fonte de incerteza, que a organização tentaria compensar. Enquanto as sociedades em geral empregariam tecnologia, leis e religião para lidar com a incerteza, as organizações fariam uso de tecnologia, regras e rituais para este fim. A tecnologia, como, por exemplo, a automação de processos, tornaria os resultados mais previsíveis a curto prazo. $\mathrm{O}$ estabelecimento de regras e regulamentos reduziria a incerteza interna causada pela imprevisibilidade do comportamento de seus membros e investidores. Finalmente, rituais seriam práticas não racionais desenvolvidas para tornar a incerteza tolerável.

Conforme destacado por Hofstede (1980), os rituais de fuga à incerteza não tornariam o futuro mais previsível; mas, ao construir uma certeza simbólica dentro da qual os membros da organização soubessem como se comportar, aliviariam um pouco do estresse causado pela incerteza. Hofstede (1980) inclui os seguintes itens na categoria de rituais para evitar incerteza:

(1) Memorandos e relatórios geralmente não conteriam nenhuma informação de que alguém fosse precisar para agir, mas seriam dispositivos para parar o tempo por um momento.

(2) O sistema contábil seria considerado um processo de absorção de incerteza, já que manteria o moral em face da incerteza, uma vez que a informação 
contábil seria freqüentemente usada com uma justificativa, após o fato de decisões que pareceriam ter sido tomadas por razões não lógicas à primeira vista.

(3) Uma parte considerável dos sistemas de planejamento não garantiria necessariamente operações mais eficazes, mas permitiria que gerentes dormissem mais tranqüilamente, à medida que acreditassem que poderiam reduzir a incerteza, adotando um planejamento mais elaborado.

(4) Uma parte considerável dos sistemas de controle seriam rituais que poderiam ser danosos, pois eles seriam capazes de encobrir questões reais por meio de certezas simbólicas, tornando as coisas menos discutíveis. Mesmo quando fosse possível medir as realizações, os sistemas de controle poderiam ainda ser ritualísticos, como, por exemplo, a checagem dos minutos na contabilidade de viagens, quando não houvesse possibilidade de julgar a sua necessidade.

(5) Especialistas que trabalham numa organização, tanto membros internos como consultores externos, transformariam incerteza em certeza aos olhos dos membros da organização, mesmo que não possuíssem maior quantidade de informação ou maior capacidade para resolver o problema.

Os rituais expostos por Hofstede (1980) parecem estar fortemente relacionados com o sistema de planejamento e controle

\section{O Aspecto Simbólico do Sistema de Planejamento e Controle}

Para compreender mais precisamente os sistema de significados envolvido dentro do sistema de planejamento e controle, é necessário discutir primeiramente os conceitos de cultura e cultura organizacional.

\section{Conceito de Cultura Organizacional}

A controvérsia existente na literatura a respeito do conceito de cultura organizacional tem suas origens na discussão relativa ao conceito de cultura em antropologia, onde existem basicamente duas linhas de pensamento: a que considera cultura como resultado da razão prática ou integrada no sistema social e a que reconhece cultura como um sistema de significados ou sistema de idéias independente do sistema social (Sahlins, 1979). Analogamente a cultura organizacional é compreendida de duas formas distintas (Smircich, 1983). Na primeira abordagem, as organizações são sistemas socioculturais em que os componentes sociais e estruturais estão totalmente integrados com as dimensões simbólica e ideativa da organização. A cultura é considerada uma variável, algo que a organização possui. Na segunda abordagem, propõe-se uma distinção conceitual e analítica 
entre sistemas culturais e sociais, levando à concepção de cultura como sistemas de idéias e símbolos, alguma coisa que a organização é.

No presente estudo compreende-se cultura organizacional dentro da segunda abordagem, ou seja, como algo socialmente produzido e reproduzido através do tempo (Meek, 1988). Segundo Meek (1988), as pessoas não absorvem passivamente significados e símbolos; elas produzem e reproduzem cultura e, no processo de reproduzi-la, podem transformá-la; entretanto também são levadas em consideração as proposições de Hofstede (1991) e Allaire e Firsirotu (1984) expostas a seguir.

Na concepção de Hofstede (1991), cultura é sempre fenômeno coletivo, porque é, pelo menos parcialmente, compartilhada com pessoas que vivem ou viveram no mesmo ambiente social onde ela foi assimilada. É a programação coletiva da mente que distingue os membros de um grupo ou categoria de pessoas de outro. Para ele, as culturas organizacionais são, em muitos aspectos, diferentes das culturas nacionais. Uma organização é sistema social de natureza diferente de uma nação, pelo menos porque os membros da organização geralmente têm certa influência na sua decisão de juntar-se a ela; só estão envolvidos durante as horas de trabalho e podem algum dia deixá-la.

Hofstede (1991) escolheu quatro termos para descrever as manifestações culturais: símbolos, heróis, rituais e valores, sendo os símbolos as manifestações mais superficiais e os valores as mais profundas, com heróis e rituais no meio.

Símbolos são palavras, gestos, figuras ou objetos que carregam um significado particular que só é reconhecido por aqueles que compartilham a cultura. Heróis são pessoas, vivas ou mortas, reais ou imaginárias, que possuem características altamente premiadas em uma cultura, e que nos servem como modelos de comportamento. Rituais são atividades coletivas, tecnicamente supérfluas para alcançar objetivos desejados, mas que, dentro de uma cultura, são consideradas como socialmente essenciais. Hofstede (1991) denominou símbolos, heróis e rituais de práticas, enfatizando que, embora eles sejam visíveis para um observador de fora, seu significado cultural encontra-se apenas na forma como essas práticas são interpretadas pelos membros da cultura.

O cerne da cultura é formado pelos valores, que são responsáveis pelas grandes tendências de preferir certas circunstâncias a outras. Eles são adquiridos tão cedo que permanecem inconscientes para aqueles que os detêm.

As manifestações culturais descritas anteriormente - símbolos, heróis, rituais e valores - desempenharão papéis distintos na cultura nacional e organizacional, contribuindo para diferenciá-las. Os resultados de pesquisa realizada por Hofstede 
entre 1985 e 1987, em 20 unidades organizacionais em 2 países europeus diferentes, mostram que pessoas em diferentes organizações revelam consideráveis diferenças em práticas, mas diferenças menores em valores. Desta forma, enquanto entre nações, diferenças culturais residem principalmente em valores e em menor grau em práticas, entre organizações, diferenças culturais residem principalmente em práticas e em menor grau em valores. Tal diversidade pode ser explicada pelos diferentes lugares de socialização (aprendizado) para valores e práticas. Os valores são adquiridos na infância, principalmente na família e na vizinhança, e mais tarde no colégio. Com 10 anos, a maior parte dos valores básicos já foi programada na cabeça de uma criança. Práticas organizacionais, por outro lado, são aprendidas por meio de socialização na empresa, na qual a maioria das pessoas entra adulta, ou seja, com a base de seus valores já formada. Com base no estudo descrito, a essência da cultura organizacional é representada por percepções compartilhadas de práticas diárias. Embora os valores dos fundadores e líderes-chaves indubitavelmente moldem as culturas organizacionais, a forma como cada cultura afeta os membros de cada organização é mediante práticas compartilhadas. Os valores dos líderes fundadores tornam-se práticas dos membros.

Referindo-se à controvérsia a respeito do conceito de cultura mencionada anteriormente e com base nos resultados da pesquisa em organizações diferentes, Hofstede (1991) propõe que as práticas seriam as características que as organizações têm. Por causa da importância do papel das práticas nas culturas organizacionais, as últimas poderiam ser consideradas de alguma forma gerenciáveis. Para ele, mudar valores coletivos em pessoas adultas numa determinada direção é extremamente difícil, se não impossível. Os valores mudam, mas não de acordo com o plano mestre de alguém. As práticas coletivas, no entanto, dependem de características organizacionais como estruturas e sistemas, e poderiam ser influenciadas de formas mais ou menos previsíveis, ao se modificarem estas estruturas e sistemas; no entanto Hofstede (1991) também acredita que as culturas organizacionais sejam de certa forma conjuntos integrados ou gestalts; assim, podem ser consideradas algo que a organização é. As mudanças em práticas representariam a margem de liberdade em influenciar esses conjuntos. Como são conjuntos, uma liderança integradora e inspiradora seria necessária para dar a essas mudanças estruturais e de sistemas um significado para as pessoas envolvidas. $\mathrm{O}$ resultado seria um padrão cultural novo e coerente.

Allaire e Firsirotu (1984) propõem que, alternadamente, algum dos seguintes fatores seja salientado como modelador da cultura e da estrutura de um sistema social: os valores e características da sociedade em que a organização se encontra, a história da organização e lideranças passadas, fatores contingenciais como tecnologia, características da indústria etc. Na prática, os três fatores sempre se combinariam e competiriam entre si para moldar a cultura organizacional. Além 
disso, observam que, mesmo levando-se em conta a visão sustentada pela escola simbólica de que pode haver múltiplos modos de integração e relação entre a cultura de uma organização e a construção e uso pessoais por cada ator desses materiais significativos, dentro da organização, evolui e subsiste uma gama de significados comuns entre os vários atores, o que facilita suas interações e serve para compreender seu mundo organizacional. A explicação para esta última constatação se basearia no fato de que, como os atores fabricam seu significado com as mesmas matérias-primas culturais, tais como influência da alta administração, história da organização, valores da cultura nacional etc, um grau considerável de compartilhamento de significado tenderá a evoluir entre atores que interagem no mesmo contexto social por um período prolongado de tempo.

O conceito de cultura organizacional adotado neste estudo parte do princípio de que a cultura sofra influências da sociedade em que se encontra, da história da organização e de lideranças passadas e de contingências externas. Embora se acredite que os atores sociais construam e destruam significados, existe uma gama de significados comuns, que facilita suas interações e que foi provavelmente aprendida por meio de socialização na empresa. Esses significados se manifestariam por meio de símbolos, heróis e rituais. A uniformidade e estabilidade de opinião sobre determinados temas pode ser conseqüência da influência de valores e crenças das lideranças sobre o grupo em relação a tais questões.

\section{O Conceito de Sistema de Planejamento e Controle}

De acordo com Gomes e Amat (1997), podem ser identificadas quatro correntes teóricas a respeito dos sistemas de controle gerencial, que se diferenciam no concernente ao aspecto que consideram ter maior influência sobre o processo de controle. Quatro aspectos são enfatizados: os aspectos formais, os aspectos psicossociais, os aspectos culturais e os aspectos macrossociais do contexto social.

A origem da abordagem que enfatiza os aspectos formais (perspectiva racional) remonta à escola clássica de Taylor e Fayol, em que se desenvolveu uma versão racional e científica da empresa. A perspectiva racional enfatiza os instrumentos formais e explícitos dos sistemas de controle, cuja implantação garantiria a eficiência e a eficácia da organização. A partir daí, o controle gerencial foi dominado pelos sistemas formais, os quais tendiam a ser concebidos de acordo com o paradigma cibernético, que enfatiza o mecanismo de feedback negativo, para reduzir desvios existentes entre resultados reais e os desejados. Também é incluída dentro dessa perspectiva a teoria da contingência, que enfatiza a necessidade de se levar em consideração as variáveis relativas ao ambiente externo.

Segundo Berry, Broadbent e Otley (1995), a suposição da abordagem clássica 
de que os objetivos da organização estão institucionalizados no orçamento, ignorando que são as pessoas dentro da organização que têm objetivos e não a organização, tem como conseqüência uma maior ênfase nos meios de controle, representados por diversas técnicas tais como orçamento, custo padrão, variâncias etc, do que no controle desejado.

De acordo com Gomes e Amat (1997), a perspectiva psicossocial do controle está associada à influência das teorias de relações humanas, processamento humano da informação e teorias de sistemas abertos. As organizações começaram a ser pensadas como resultantes não só de fatores formais, mas também das ações de indivíduos e grupos que buscam alcançar seus próprios objetivos. A crença básica é a de que, ao se atribuir maior ênfase às pessoas, é possível conciliar os objetivos individuais com os objetivos organizacionais, aumentando tanto a motivação como a capacidade de autocontrole das próprias pessoas.

A perspectiva cultural do controle surge a partir do conceito de cultura desenvolvido pela teoria das organizações, quando uma parte das pesquisas passa a sugerir que os sistemas de controle gerencial estariam integrados dentro de um sistema organizacional, que compreenderia os valores da organização, englobando aspectos mais amplos do que os aspectos formais e psicossociais (Gomes e Amat, 1997).

Berry, Broadbent e Otley (1995) referem-se às revisões de Smircich (1983) e Allaire e Firsirotu (1984), expostas neste estudo na definição do conceito de cultura organizacional, para ressaltar que a diferença mais significativa entre as abordagens de cultura em organizações surge entre a visão de que cultura é uma variável que pode ser manipulada para atingir os resultados corretos para a organização, e a visão de que cultura é um elemento dinâmico e simbólico, que deve ser considerado, mas que não pode ser determinado externamente.

Ilustrando esta primeira concepção de cultura organizacional, o modelo de Flamholtz (1996, p. 603-604) ressalta a importância da cultura organizacional na administração dos sistemas de controle gerencial: "cultura é, de fato, o ponto de partida para o desenho do sistema de controle organizacional. Apesar do fato de que muda devagar e tipicamente com grande dificuldade, a cultura organizacional é uma variável. Está sujeita a influências, podendo ser produto da decisão gerencial".

Flamholtz (1996) ressalta que o sistema de controle organizacional não pode ser visto como conjunto de técnicas de controle como orçamentos, medidas e relatórios contábeis, pois estes mecanismos de controle não motivam ou controlam o comportamento dos gerentes se não forem consistentes com os valores da cultura organizacional e características da estrutura organizacional. Assim, propõe um 
modelo de sistemas que consistiria em três partes: o sistema de controle central, a estrutura organizacional e a cultura organizacional. Juntos, estes três componentes seriam denominados sistema de macrocontrole. O sistema de controle central seria uma estrutura cibernética constituída por quatro elementos: planejamento, operações, mensuração e avaliação-recompensa.

Na visão simbólica da cultura, a cultura é construída pelos atores sociais no dia-a-dia, sendo possível que outros grupos, além dos gerentes, desenvolvam sua própria cultura ou resistam à imposição cultural. Para Berry, Broadbent e Otley (1995) essas suposições consideram cultura um artefato simbólico, que emergiria e teria relação com o contexto e a história. Nesta concepção, controle é muito mais um ato de equilíbrio político, significando mais trabalhar dentro do sistema cultural do que procurar moldá-lo.

Finalmente, a perspectiva dos aspectos macrossociais procura estudar os sistemas de controle gerencial dentro de seu contexto ideológico, social e político. Dentro dessa perspectiva destaca-se a corrente cross-cultural, que procura analisar a influência da cultura nacional sobre o funcionamento do processo de planejamento e controle (Gomes e Amat, 1997). O estudo de Hofstede (1980) é um dos mais conhecidos e importantes dessa abordagem: a partir dele, vários estudos foram realizados, visando a testar ou aprofundar características das dimensões por ele identificadas, contribuindo para destacar a relevância do estudo da influência da cultura nacional nas organizações.

Ainda dentro dos estudos cross-cultural, os resultados da pesquisa de Binberg e Snodgrass (1988) mostram que a cultura afeta não só a natureza dos sistemas formais de controle, mas também a percepção dos trabalhadores a respeito desses. A forma como Birnberg e Snodgrass (1988, p. 449) percebem a influência da cultura no sistema de controle é apresentada a seguir.

"A cultura consiste em uma variedade de elementos. Estes incluem valores, crenças e padrões de comportamento. Então, quando o sistema de controle gerencial é discutido em um contexto cross-cultural, ele acrescenta outra dimensão à análise. Membros de diferentes grupos culturais podem reagir diferentemente ao mesmo mecanismo de controle ou requerer diferentes mecanismos de controle para atingir o mesmo comportamento. Assim, não existe razão para acreditar que um único sistema de controle gerencial seja apropriado para todos os grupos culturais".

Para Binberg e Snodgrass (1988), a cultura funcionaria como filtro, produzindo dois efeitos no processo de controle gerencial. Em primeiro lugar, poderia afetar a escolha do estímulo ao qual o indivíduo atende, fazendo com que os indivíduos procurem certas classes de estímulos e ignorem outras. O segundo efeito seria 
relativo ao julgamento de valor a respeito do estímulo, como, por exemplo, sua relevância e credibilidade.

O conceito de sistema de planejamento e controle adotado neste estudo procura considerar, além dos aspectos formais do sistema, aqueles relativos à estrutura organizacional e à cultura organizacional e nacional. Convém ressaltar entretanto que, ao contrário de Flamholtz (1996), não se admite que a cultura seja uma variável, senão que ela seja construída pelos atores sociais no dia-a-dia. Admitese, no entanto que, conforme proposto por Allaire e Firsirotu (1984), dentro da organização evolua e subsista uma gama de significados comuns entre os vários atores, o que facilita suas interações e serve para compreender seu mundo organizacional.

\section{Metodologia}

\section{O Método de Pesquisa}

A metodologia empregada neste estudo comportou entrevistas abertas e profundas realizadas dentro da empresa analisada.

Optou-se pelo método de pesquisa qualitativo em função do conceito de cultura organizacional adotado, o qual pressupõe que a realidade é produto social, que não pode ser entendido longe dos significados intersubjetivos dos atores sociais envolvidos na sua construção.

Segundo Morgan e Smircich (1980) os métodos quantitativos usados em ciências sociais, que se baseiam principalmente nos métodos de ciências naturais, são apropriados para capturar uma visão do mundo social como estrutura concreta. Ao aplicar abordagens quantitativas, os cientistas estão presumindo que o mundo social se presta a uma forma objetiva de mensuração, e que o cientista é capaz de revelar a natureza desse mundo, examinando leis entre elementos que, para uma definição e mensuração acuradas, têm de ser abstraídos de seu contexto. Uma vez que se relaxe a suposição ontológica de que o mundo é estrutura concreta, e se admita que os seres humanos, longe de meramente responderem ao mundo social, podem ativamente contribuir para a sua criação, os métodos dominantes (positivistas) tornam-se cada vez mais insatisfatórios, ou mesmo inapropriados.

Rosen (1991, p. 7) aponta que a adoção do método positivista pressupõe causalidade e procura sua explicação, acreditando que "os processos relevantes para o estudo podem ser reduzidos a variáveis dependentes e independentes, que podem 
ser captadas por meio de questionários ou experiências, e predominantemente analisadas, usando técnicas quantitativas". Segundo Rose (1988) o uso de uma metodologia superficial, que apenas caracterize a cultura dominante, deve falhar em captar os múltiplos significados atribuídos aos eventos organizacionais por diferentes interesses.

De acordo com Bryman (1995), a característica mais marcante do método de pesquisa qualitativo é o seu empenho em ver ações, eventos, normas, valores etc, sob a perspectiva das pessoas que estão sendo estudadas. Ainda segundo Bryman (1995), o método mais conhecido de pesquisa qualitativa é a observação participante, na qual existe uma imersão do autor dentro do grupo que ele pretende estudar. Tal estratégia é muito utilizada nos estudos etnográficos realizados em antropologia; entretanto a observação participante não é o único método de pesquisa qualitativa. Para Bryman (1995) as entrevistas não estruturadas, nas quais o autor proporciona uma orientação mínima e permite considerável espaço livre ao entrevistado, configuram uma técnica vantajosa. O objetivo das entrevistas é muito diferente das entrevistas do tipo survey, à medida que proporcionam maior liberdade para divagações por parte do entrevistado, nas quais ele revela temas que são importantes para ele. Essa atitude é consistente com a preocupação de captar informações sob a perspectiva daqueles que estão sendo investigados.

A pesquisa qualitativa vem sendo empregada com sucesso nos últimos anos em pesquisas acadêmicas de administração. Mais especificamente, examinando as culturas francesa, americana e holandesa à luz de estudos etnográficos, D'Iribarne (1997) verificou que os resultados alcançados contradiziam aqueles obtidos no estudo de Hofstede (1980).

Segundo D'Iribarne (1997) as divergências encontradas entre seus estudos e o de Hofstede (1980) podem ser explicadas pela maneira como os índices foram construídos. A seleção das perguntas e a interpretação das respostas às perguntas utilizadas na construção do índice, parecem colocar em dúvida o significado preciso do ordenamento dos países. Para ele, as questões do estudo de Hofstede (1980) foram formuladas numa época em que o conhecimento teórico dos domínios relevantes era praticamente inexistente; entretanto a considerável subjetividade das escolhas das questões usadas em abordagens quantitativas fica facilmente escondida sob a aparente objetividade dos números.

Assim, tendo em vista o forte aspecto simbólico envolvido na influência da cultura nacional no sistema de planejamento e controle, bem como a suposição de que a cultura organizacional está em constante mudança, sendo alterada pela ação de seus membros e, ao mesmo tempo, influenciando suas ações, justifica-se a realização de uma abordagem qualitativa. 


\section{A Empresa e os Informantes}

Os nomes das empresas envolvidas na análise foram alterados para nomes fictícios. Este procedimento é eticamente recomendável e tem por finalidade evitar que a identificação da empresa venha a prejudicá-la de alguma forma. Assim, o nome da holding da qual a empresa multinacional faz parte foi alterado para Multi, enquanto a empresa multinacional e sua subsidiária foram denominadas Partic.

A Multi, um grupo britânico, está dividido em três grandes blocos: alimentos, produtos pessoais e produtos químicos ou industriais. A Partic é uma empresa da área de produtos químicos. A matriz da Partic se localiza no noroeste da Inglaterra.

$\mathrm{Na}$ área de produtos químicos da Multi, a coordenação é muito semelhante em todas as empresas, sendo a ligação com o centro muito forte. Os gerentes da Multi dentro de cada país costumam ser transferidos para outras companhias do grupo.

De um negócio exportador, restrito à Europa do Norte, a Partic vem-se transformando, desde 1988, em companhia internacional. Ela apresenta estrutura matricial composta de 3 categorias básicas de produtos, as quais estão espalhadas por 10 unidades estratégicas de negócios. Cada unidade estratégica de negócio tem um time composto por um líder, uma pessoa na área comercial e uma pessoa de produção, que é responsável pelos resultados da unidade de negócios em termos mundiais. O líder está localizado perto do maior mercado.

As políticas de recursos humanos da Multi são aplicadas à Partic da Inglaterra, mas com razoável grau de liberdade, de modo que ela deve, basicamente, cumprir as metas de lucro e produzir bons clientes. A Multi apresenta uma estrutura que varia de acordo com o país em que se localiza. No caso do Brasil, a Partic não existe formalmente, sendo sua subsidiária, por conveniência fiscal, uma divisão legal da Multi brasileira. Apesar disso, para maior clareza, a subsidiária brasileira será considerada a Partic do Brasil. Ela segue as políticas da Multi apenas onde isso tem sentido, como, por exemplo, na área de recursos humanos, para aproveitar a sinergia de serviços. Nas questões operacionais, adota a orientação da Partic britânica. A integração da Partic com a Multi no Brasil também visa fazer com que os membros da Partic brasileira se sintam menos isolados e mais prestigiados, já que a Partic britânica fica distante e sua subsidiária no Brasil tem tamanho muito reduzido.

As operações da Partic no Brasil tiveram início em 1980. Entre 1980 e 1989 havia apenas um escritório de vendas. As duas fábricas atualmente existentes na empresa foram adquiridas em 1989 e 1994. Na subsidiária brasileira, além das 
áreas administrativas que englobam sistemas, compras e recursos humanos, existem duas divisões comerciais. Cada divisão é responsável pela venda de um grupo de produtos. Na época das entrevistas, uma delas era comandada por um britânico residente no Brasil há cerca de 3 anos e que estava de partida para a Inglaterra.

\section{As Entrevistas}

Para determinar as questões que formariam a base para as entrevistas realizadas no estudo, buscou-se na literatura referências a possíveis influências da dimensão fuga à incerteza nos subsistemas que compõem o sistema de planejamento e controle. Assim, foram formuladas as perguntas da pesquisa e as proposições a elas associadas. Estas últimas foram fundamentadas nas previsões teóricas a respeito dos comportamentos esperados na matriz (baixa fuga à incerteza) e na subsidiária (alta fuga à incerteza). A partir das proposições da pesquisa foram elaboradas as questões que serviram de base para as entrevistas realizadas tanto na matriz britânica quanto na subsidiária brasileira.

O roteiro básico das entrevistas consistiu em 46 perguntas das quais 21 se referiam ao subsistema de planejamento, 3 ao subsistema de monitorização, 5 ao subsistema de avaliação de desempenho, 5 ao subsistema de recompensa, 8 à estrutura organizacional e 4 à cultura organizacional.

As entrevistas realizadas na Inglaterra ocorreram em março de 1996, sendo pouco estruturadas, pois visavam a captar aspectos gerais da estrutura e do sistema de planejamento e controle, assim como a imagem, percepção e conhecimento que a matriz possuía a respeito da subsidiária brasileira. Foram entrevistados dois britânicos, o vice-presidente comercial e o diretor responsável pela área de planejamento e controle, e um brasileiro. O último morava havia 2 anos na Inglaterra e estava exercendo a função de gerente de desenvolvimento de negócios.

As entrevistas realizadas no Brasil ocorreram em julho de 1996, procurando atingir o maior número possível de pessoas do grupo, do qual apenas a secretária não conseguiu concluir a entrevista por falta de tempo. Assim, foram entrevistadas 14 das 15 pessoas alocadas na subsidiária. Apesar de se basearem no mesmo roteiro, as perguntas foram abertas, de modo que se permitisse que os depoimentos refletissem a importância que os assuntos tinham para os informantes, já que a intensidade com que os temas foram abordados ficou a critério deles. Além disso, dependendo da função exercida pelos entrevistados, algumas perguntas foram supressas, por não serem consideradas pertinentes. 


\section{Resultados}

Os resultados mostram que algumas diferenças em aspectos do sistema de planejamento e controle, previstas na teoria como decorrentes de diferentes níveis de fuga à incerteza, puderam ser observadas na empresa analisada. Embora os depoimentos pareçam confirmar a grande maioria das proposições teóricas, os motivos para que algumas delas não tenham sido evidenciadas podem estar ligados a contingências externas, a outras dimensões culturais, que anulem certos efeitos da dimensão em análise, ou ainda, à influência da cultura organizacional.

\section{Cultura Organizacional}

De maneira geral, três características importantes puderam ser identificadas dentro da subsidiária brasileira. Em primeiro lugar, a tensão entre brasileiros e britânicos, em grande parte decorrente de diferentes orientações. As declarações parecem enfatizar a importância do ambiente de trabalho e das pessoas para os brasileiros, o que não parece preocupação da matriz, cuja atenção está voltada para as tarefas e para a cobrança de resultados. Em segundo lugar, percebe-se o paradoxo da pequena empresa dentro da grande, dando origem a um sentimento de inferioridade e frustração decorrente de se trabalhar na Partic do Brasil. A maioria das pessoas entra na empresa atraída pelas qualidades da Multi; só mais tarde descobre que as possibilidades de carreira dentro da Partic não são as mesmas que existem na Multi. Finalmente, os depoimentos sugerem que a identidade da Partic ainda esteja em formação, principalmente após a aquisição da última fábrica, cujos funcionários incorporados à subsidiária apresentam uma cultura muito definida e distinta da existente no restante da Partic do Brasil.

\section{Subsistema de Planejamento}

Dentro do subsistema de planejamento, algumas diferenças parecem marcar a forma de os britânicos e brasileiros analisarem o ambiente, selecionarem e interpretarem informações, estabelecerem prioridades e fixarem metas.

Com relação ao exame do ambiente, quatro pontos foram abordados: a incerteza percebida no ambiente; o controle sobre o ambiente; a importância dada ao planejamento; a quantidade de informações coletadas no ambiente.

Comparando-se o discurso dos informantes, verifica-se que a subsidiária brasileira em relação à matriz britânica percebe menos incerteza no ambiente, procurando, em função disso, menor quantidade de informação neste. Por outro lado, o grupo brasileiro admite ter menor controle sobre o curso dos eventos e, portanto, 
sobre a realização das metas previstas no planejamento. Os depoimentos sugerem que os gerentes britânicos por acreditarem ter mais controle sobre os eventos, atribuiriam maior importância ao estabelecimento de objetivos, porque julgariam que a obtenção de resultados dependeria do seu empenho. Como conseqüência desse pensamento, o grupo britânico procuraria mais informação no ambiente para reduzir incertezas, em comparação com seus colegas brasileiros. Essas conclusões confirmam as proposições teóricas formuladas, sugerindo que, no que se refere ao exame do ambiente, os resultados encontrados seriam consistentes com o que seria esperado com base na teoria revista.

No que se refere a seleção e interpretação das informações, foram examinados o tipo de abordagem à resolução de problemas, a quantidade de informação necessária para apoiar as decisões, a forma de transmitir conhecimento e a intensidade de uso de técnicas quantitativas.

Comparando-se o discurso dos atores sociais com o que foi sugerido na literatura, conclui-se que os resultados parecem caminhar no sentido inverso ao esperado: as características identificadas como relativas à matriz britânica são congruentes com o comportamento previsto para tomada de decisões numa sociedade com alta fuga à incerteza; busca-se melhor caminho por meio de um raciocínio passo a passo, com base em muitas informações e com a utilização intensa de técnicas estatísticas. De forma oposta, na subsidiária brasileira seriam procuradas soluções mais práticas, por meio de um raciocínio indutivo, com as informações disponíveis e pouco uso de técnicas quantitativas.

Dentro do estabelecimento de prioridades, examinaram-se suposições com relação à mudanças, suposições com relação à incerteza e suposições com relação ao tempo.

Com base na análise dos depoimentos, parte das proposições teóricas parece confirmada. As declarações sugerem que, comparada com a matriz, a subsidiária apresenta maior resistência à abertura para o exterior, tanto na questão da aceitação de outras culturas e em programas de intercâmbio, como em relação à própria abertura da economia. A subsidiária brasileira também se diferencia da matriz na sua política de recursos humanos, dando maior ênfase à seleção seguida de treinamento, demonstrando simultaneamente duas características relacionadas à alta fuga à incerteza: não acreditar que as pessoas possam mudar e evitar a busca de recursos fora. Além disso, a reação do grupo brasileiro a situações imprevistas tais como pedidos não programados demonstrou ser mais agressiva do que a do grupo britânico, como havia sido conjecturado. No que concerne às suposições com relação ao tempo, pode ser detectada com muita nitidez uma preferência dos informantes brasileiros pelo curto prazo, a qual vem acompanhada de maior senso de urgência, contrastando com a maior valorização dada ao longo prazo pelo 
grupo britânico. Finalmente, a idéia de que tempo é dinheiro não se destacou dentro dos discursos dos atores sociais como ponto que pudesse diferenciar os dois grupos analisados. A maioria dos informantes da subsidiária parece não compartilhar da idéia de que tempo é dinheiro, como seria esperado para culturas com índices mais elevados de fuga à incerteza.

Dentro do subsistema de planejamento, a fixação de metas foi o último aspecto estudado, englobando os seguintes sub-temas: processo de tomada de decisão, necessidade de harmonia, competição, tolerância com opiniões diferentes, folga no orçamento, controle de emoções, respostas precisas e integração de recursos humanos.

Comparando-se as declarações dos atores sociais dos dois grupos estudados, conclui-se que o grupo brasileiro parece ter preferência por decisões em grupo ou sob orientação do chefe em função do risco nelas envolvido. Como conseqüência, as pessoas têm maior capacidade de tomar decisões sem necessidade de consenso ou aprovação de um superior hierárquico, tolerando melhor o exercício de discrição na matriz britânica do que na subsidiária brasileira. Assim, no que se refere ao processo de tomada de decisão, as declarações dos informantes se mostraram congruentes com as proposições teóricas apresentadas. Confirmando o comportamento previsto com base na teoria, o grupo brasileiro parece ter maior dificuldade de controlar suas emoções do que o grupo britânico. Em função disso, existiria maior tendência a evitar conflitos e competição na subsidiária, onde também haveria menor tolerância com opiniões diferentes e com gerentes estrangeiros. A necessidade de respostas precisas não foi evidenciada no discurso dos informantes britânicos da mesma forma do que no dos brasileiros, o que talvez indique que a preocupação de que os chefes tenham conhecimento suficiente para ocupar o cargo seja mais acentuada na subsidiária. Por outro lado, ao contrário do sugerido na literatura, foram encontrados indícios de maior aprovação da utilização de folgas no orçamento na matriz, já que os britânicos consideram os números apresentados pela subsidiária muito otimistas. Finalmente, o fato de terem sido encontradas diferentes atitudes com relação à integração de recursos humanos nas duas divisões da subsidiária sugere que a atitude da gerência pode ter influência na integração de recursos humanos. É curioso notar que justamente na divisão do gerente britânico se concentram os problemas de relacionamento, contrariando o que seria esperado pela teoria.

\section{Subsistema de Monitorização}

Dentro do subsistema de monitorização, examinou-se a influência das diferenças culturais nos aspectos relacionados com a comparação daquilo que foi realizado com o que foi orçado, entre os quais se destacam: a abordagem do sistema de 
controle, a atitude em relação a feedback, reversão de decisões erradas e tendência a evitar notícias ruins.

Comparando as declarações dos informantes britânicos e brasileiros, percebese que, conforme era previsto na literatura, o grupo brasileiro se sente mais confortável com um sistema de controle mais normativo, enquanto a preferência do grupo britânico recai sobre um sistema de controle baseado na cultura. Outra proposição teórica, que parece verdadeira, é a referente às diferenças de comportamento entre os dois grupos. Tendo em vista o controle que os informantes britânicos julgam ter sobre seu futuro, o uso de feedback para melhorar o desempenho passado parece mais intenso entre eles do que entre os informantes brasileiros, os quais geralmente culpam outras pessoas ou condições externas por seu desempenho ruim, não parecendo acreditar que possuam controle sobre o curso dos eventos. Além disso, surgiram indícios de perda da face como conseqüência de feedback negativo entre os informantes brasileiros, o que, juntamente com uma tendência a evitar notícias ruins, também sugerida pelo grupo, parece acarretar demora na correção de desvios, causando atrito com o grupo estudado britânico. A única proposição que não teria sido evidenciada foi a relativa a uma maior capacidade, por parte do grupo britânico, de reverter decisões que se mostram incorretas, em função da forte repercussão política que esta atitude poderia acarretar.

\section{Subsistema de Avaliação}

Dentro do subsistema de avaliação, os aspectos selecionados como passíveis de sofrerem a influência de diferentes níveis de fuga à incerteza foram: prazo de avaliação de desempenho, medidas de avaliação contábeis, controlabilidade dos orçamentos, atribuição de responsabilidade, ênfase em realização versus ênfase em atribuição, orientação para as pessoas versus orientação para as tarefas.

Comparando-se as atitudes dos dois grupos em relação ao subsistema de avaliação, os depoimentos indicam que algumas proposições teóricas poderiam ser corroboradas. Em primeiro lugar, os brasileiros sentem-se mais pressionados por medidas de avaliação contábeis, tornando-se fundamental para eles poder justificar desvios junto aos seus chefes. Em função disso, também se evidencia, dentro da subsidiária, maior preocupação com filtros de controlabilidade e menor ênfase em atribuição de responsabilidades em comparação com a matriz. O destaque dado pela matriz a resultados parece indicar que a avaliação é muito mais centrada na realização, enquanto os informantes brasileiros, revelando maior ênfase em atribuição, parecem apreciar a inclusão de outros aspectos no subsistema de avaliação. Finalmente, cabe ressaltar que, contrariando o comportamento previsto para sociedades com alta fuga à incerteza, os informantes brasileiros declara- 
ram-se mais orientados para as pessoas do que para as tarefas e menos confortáveis do que os britânicos com as avaliações de curto prazo. Com relação a este último aspecto, o informante britânico lotado na subsidiária afirmou que, embora em ambos os países a avaliação seja de curto prazo, no Brasil as pessoas ficam no emprego por prazo mais longo e preocupam-se mais em acompanhar o mercado a longo prazo.

\section{Subsistema de Recompensa}

Dentro do subsistema de recompensa, foram estudados os fatores de motivação e os tipos de recompensas preferidas, abordando-se os seguintes aspectos: tendência de comportamento semelhante a teoria $\mathrm{X}$ ou a teoria $\mathrm{Y}$, necessidade de segurança no trabalho versus necessidade de realização, alienação em relação à vida organizacional, esquemas de remuneração que envolvem risco, preferência por recompensas extrínsecas versus intrínsecas e crença dos empregados no interesse da empresa no seu bem-estar.

Conforme sugerido na teoria, os depoimentos indicam uma preferência por parte dos informantes brasileiros por recompensas extrínsecas, principalmente financeiras, juntamente com ênfase na estruturação das tarefas. Conforme declarado pelo gerente de divisão britânico, "do momento em que estão contentes, ganhando dinheiro, é suficiente, está OK”. Dentro da subsidiária, evidenciou-se até mesmo certo repúdio ao trabalho após o expediente. Como justamente o grupo comandado pelo britânico é que costuma ficar após o horário, isto pode indicar diferença cultural. Além disso, os brasileiros se mostraram confortáveis com tarefas bem estruturadas, o que não parece preocupação dos britânicos. Assim, esses aspectos tendem a sugerir que, na subsidiária brasileira, melhorar a qualidade do trabalho implica oferecer mais segurança e, possivelmente, mais estrutura da tarefa, enquanto na matriz britânica os esforços para melhorar a qualidade no trabalho devem enfocar o enriquecimento do trabalho. Por outro lado, a declaração do informante britânico lotado na subsidiária a respeito de seus funcionários estaria mais próxima do pensamento que consta da teoria $\mathrm{X}$ do que a visão do grupo brasileiro, invertendo a relação esperada com base na teoria. Também em oposição à teoria, as declarações sugerem que tanto os informantes brasileiros como os britânicos parecem colocar a segurança acima de realização; entretanto a ênfase em segurança na Europa parece decorrente do processo de reestruturação de empresas, que estaria ocorrendo nos últimos anos. Os depoimentos também não parecem corroborar maior preferência por esquemas de remuneração que envolvam risco na matriz, como sugerido na literatura, apesar de evidenciarem que existiria forte aversão a essas formas de recompensa na subsidiária. As causas para essa divergência em relação à teoria podem ser as mesmas citadas para justificar a necessidade de segurança por parte dos 
europeus. Também não pode ser confirmada a proposição teórica de que a alienação da vida organizacional é maior na subsidiária brasileira, já que o não envolvimento real dos funcionários nas decisões parece característica da empresa em termos mundiais. Finalmente, apesar de se verificar que os brasileiros, de maneira geral, não acreditam que a empresa esteja interessada no seu bemestar, esta crença parece estender-se à matriz. Os dois últimos aspectos poderiam ser interpretados como características da cultura organizacional da Partic, tanto na Inglaterra como no Brasil.

\section{Estrutura Organizacional}

Os principais aspectos estudados com relação à estrutura organizacional foram: estruturas orgânicas versus mecânicas, especialização, aceitação da estrutura matricial, comunicação e flexibilidade.

Os depoimentos confirmam que os informantes britânicos se sentem mais confortáveis com estruturas orgânicas, enquanto os informantes brasileiros preferem estruturas mecânicas. Apesar de existir maior número de especialistas na Inglaterra, os informantes brasileiros afirmaram ter preferência por esta posição, acrescentando que, muitas vezes, acabam tornando-se gerentes por causa da remuneração envolvida. As declarações evidenciam ainda que, embora os dois grupos de atores sociais admitam que a comunicação entre eles é muito intensa, os brasileiros a consideram mais falha, possivelmente indicando maior necessidade de clareza por parte deles nessa questão. Ao contrário dos itens anteriores, alguns resultados não parecem consistentes com algumas proposições do estudo. Em primeiro lugar, apesar da necessidade de respeitar a hierarquia e obter respostas precisas do chefe, não pareceu haver dificuldade em aceitar a estrutura matricial no Brasil, já que o chefe hierárquico de cada pessoa estaria bem definido, havendo apenas reclamações quanto à "quantidade excessiva de informação demandada". Como essa dificuldade também é sentida pelos britânicos, não se pode afirmar que eles se sintam mais confortáveis com estruturas matriciais do que a subsidiária brasileira. O principal problema alegado nesta estrutura - objetivos conflitantes entre chefes - não foi evidenciado na subsidiária, porque aí os funcionários considerariam chefe apenas seu superior hierárquico, estabelecendo um fluxo de comunicação com ele, que o manteria informado de todos os seus passos. Finalmente, os informantes consideram que haveria maior flexibilidade na subsidiária do que na matriz, de forma oposta ao que seria esperado para um país com alta fuga à incerteza e com preferência por estruturas mecânicas. 


\section{CONCLUSÓES}

A pesquisa parece ter permitido que fossem evidenciados nos dois grupos aspectos que poderiam ter alguma influência sobre o sistema de planejamento e controle. A identificação de tais pontos poderia ajudar a compreender problemas que estariam ocorrendo dentro do sistema de planejamento e controle da empresa e que não poderiam ser solucionados pelo sistema formal. O conhecimento de valores do grupo brasileiro, tais como necessidade de harmonia e dificuldade em transmitir notícias ruins, permitiria identificar causas de atritos em relação ao cumprimento das metas entre os dois grupos que, na maioria das vezes, seriam atribuídas à situação econômica e política. Por outro lado, a identificação de valores comuns poderia contribuir para criar pontos de identificação entre as duas equipes, melhorando o relacionamento entre elas ou, ainda, ajudando a formular políticas que incluíssem esses aspectos valorizados tanto pela subsidiária quanto pela matriz. Por exemplo, políticas de compensação que envolvessem riscos, deveriam ser evitadas, já que nenhum dos dois grupos se mostrou favorável a elas.

Verifica-se, ainda, uma complementação entre as pesquisas quantitativa e qualitativa, uma vez que a análise conseguiu aprofundar o que havia sido sugerido em alguns estudos quantitativos encontrados na literatura. Determinados pontos previstos em pesquisas anteriores foram confirmados, enquanto, em outros casos, nos quais havia mais de um comportamento possível, pode-se escolher entre as alternativas apresentadas. Em outro extremo, alguns aspectos não puderam ser corroborados ou mostraram-se totalmente opostos ao que seria esperado com base na teoria, sugerindo que outros fatores, tais como outros aspectos culturais atuam em sentido contrário ao da dimensão fuga à incerteza. Em particular, destacamse aqueles peculiares à cultura brasileira, como o jeitinho, o qual possivelmente permitiria acomodar flexibilidade e preferência por um sistema de controle normativo, ou ainda, como a característica marcadamente relacional da sociedade brasileira que, possivelmente, poderia explicar a verificada orientação para pessoas por parte dos gerentes brasileiros, quando a literatura sugere que sociedades com alta fuga à incerteza apresentariam maior orientação para tarefas. Essas e outras idiossincrasias da cultura brasileira deveriam ser evidenciadas para que se conheçam os limites da aplicação de uma dimensão tão ampla como fuga à incerteza a essa cultura. Tal procedimento permitiria empregar com maior segurança essa dimensão às empresas brasileiras, o que, como sugere este estudo, pode ser muito útil nas suas relações com empresas localizadas em outras culturas. Além dos aspectos relativos à cultura brasileira, contingências externas também poderiam ser levadas em conta, para explicar os resultados que contrariam a teoria. Por exemplo, a onda de reestruturação de empresas na Europa talvez possa explicar a ênfase dos britânicos em segurança no emprego, em oposição ao que seria espera- 
do com base somente em aspectos culturais. Finalmente, a cultura organizacional poderia explicar as semelhanças detectadas nos dois grupos, como as referentes à alienação dos funcionários em relação à vida organizacional ou à crença deles no desinteresse da empresa por seu bem-estar, que também não haviam sido previstas na literatura.

\section{NotA}

${ }^{1}$ Face refere-se ao respeito, orgulho e dignidade de um indivíduo em conseqüência da sua posição na sociedade. A norma prescreve que a dignidade de um indivíduo, mesmo em matérias triviais, deve ser defendida e respeitada.

\section{ReFERÊnCIAS BiblográFICAS}

ADLER, N. J;

BARTHOLOMEW, S.

Academic and professional communities of discourse : generating knowledge on transnational human resource management. Journal of International Business Studies, p. 551-569, Third Quarter 1992.

ALLAIRE, Y.;

FIRSIROTU, M. E.

Theories of organizational culture. Organization Studies, v. 5, n.3, p. 193-226, 1984.

BERRY, A. J.;

BROADBENT, J.;

OTLEY, D.

Management control : theories, issues and practices. London : Macmillan, 1995.

BIRNBERG, J. G.;

SNODGRASS, C.

Culture and control : a field study. Accounting, Organizations and Society, v. 13, n. 5, p. 447-464, 1988.

BRYMAN, A.

Quantity and quality in social research. London : Routledge, 1995.

D'IRIBARNE, P.

The usefulness of an ethnographic approach to the international comparison of organizations. International Studies of Marketing \& Organizations, v. 26, n. 4, p. 30-47, 1997. 
FLAMHOLTZ, E.

Effective organizational control : a framework, applications, and implications.

European Management Journal, v. 14, n. 6, p. 596-611, Dec. 1996.

FONSECA, A. C. P. D.

Percepções de incerteza em um sistema de planejamento e controle : um estudo etnográfico Brasil-Inglaterra. Rio de Janeiro, 1997. Tese (Doutorado) - Instituto de Pós-Graduação e Pesquisa em Administração, Universidade Federal do Rio de Janeiro.

GOMES, J. S.;

AMAT, J. M.

Controle de gestão : uma abordagem contextual e organizacional. São Paulo : Atlas, 1997.

HOFSTEDE, G.

Culture's consequences : international differences in workrelated values. London: Sage Publications, 1980.

\section{Culture and management} development. Discussion Paper 28, International Labour Office, Management Development Branch, Training Department, Geneva, 1983.

Cultures and organizations : software of the mind. New York : McGraw-Hill, 1991.

The business of international business is culture. International Business Review, v. 3, n. 1, p. 0114, 1994.

MEEK, V. L.

Organizational culture : origins and weaknesses. Organizational Studies, v. 9, n. 4, p. 453-473, 1988.

MORGAN, G.;

SMIRCICH, L.

The case for qualitative research. Academy of Management Review, v. 5, n. 4, p. 491-500, 1980.

ROSE, R. A.

Organizations as multiple cultures : a rule theory analysis. Human Relations, v. 41, n. 2, p. 139-170, 1988.

ROSEN, M.

Coming to terms with the field : understanding and doing organizational ethnography. Journal of Management Studies, v. 28, n. 1, p. 01-24, Jan. 1991.

SAHLINS, M.

Cultura e razão prática. Rio de Janeiro : Zahar, 1979.

SMIRCICH, L.

Concepts of culture and organizational analysis. Administrative Science Quarterly, v. 28, p. 339-358, 1983. 
SONDERGAARD, M.

Research note - Hofstede's consequences : a study of reviews, citations and replications. Organization Studies, v. 15, n. 3, p. 447-456, 1994. 